\title{
The Latest Drugs in Development That Reduce Intraocular Pressure in Ocular Hypertension and Glaucoma
}

This article was published in the following Dove Press journal: Journal of Experimental Pharmacology

\author{
Viran Jayanetti ${ }^{1}$ \\ Sartaj Sandhu ${ }^{2}$ \\ Jed A Lusthaus $\mathbb{D}^{3}$ \\ 'Prince of Wales Hospital, Sydney, New \\ South Wales, Australia; ${ }^{2}$ Sydney Eye \\ Hospital, Sydney, New South Wales, \\ Australia; ${ }^{3}$ Glaucoma Unit, Sydney Eye \\ Hospital, Sydney, New South Wales, \\ Australia
}

\begin{abstract}
Glaucoma causes irreversible vision loss, with elevated intraocular pressure (IOP) being the only known modifiable risk factor. There are a variety of medical and interventional options for lowering IOP; however, despite these treatments, glaucoma continues to be a leading cause of visual impairment. Further research continues to strive for treatment options with improved side effect profiles, additional IOP-lowering effects, and ease of use. This review provides a brief summary of current IOP-lowering therapies and then outlines pipeline ocular hypotensive agents, their mechanisms of action, benefits, and side effect profiles. Advancements are seen within currently used eye drop classes such as prostaglandin analogues, Rho kinase inhibitors and nitric oxide donors, whilst there are also new drug classes, such as tyrosine protein kinase activators. Most developing drugs are topical drop formulations, with a number already having entered Phase III trials. Alternative drug delivery methods are also in development and will be briefly discussed. Pharmacological and drug delivery developments continue to provide glaucoma patients and clinicians with new options and the promise of better outcomes, particularly in terms of improved tolerance and reduced frequency of dosing.
\end{abstract}

Keywords: glaucoma, ocular hypertension, intraocular pressure, ocular hypotensive drugs

\section{Introduction}

Glaucoma is a leading cause of visual impairment in the world. It is a neurodegenerative disease characterised by distinctive optic nerve changes with corresponding visual field defects. The only known modifiable risk factor for glaucoma is elevated intraocular pressure (IOP). Patients with elevated IOP, but without glaucomatous visual field changes or optic nerve damage, are diagnosed with ocular hypertension (OHT). Ocular hypertension can progress to glaucoma, and when combined with other risk factors such as family history, increased cup-todisc ratio or reduced central corneal thickness, may require IOP lowering treatment. $^{1,2}$ Elevated IOP is the only modifiable risk factor for glaucoma, and so treatment strategies concentrate on lowering IOP.

Intraocular pressure is dependent on the balance between aqueous humour production and outflow within the anterior segment of the eye. Aqueous production, or inflow, originates from the ciliary body, while outflow is achieved via two pathways: the conventional and unconventional pathways. The conventional outflow pathway drains through the trabecular meshwork, Schlemm's canal, and into the episcleral veins. The unconventional pathway drains aqueous through the ciliary
Correspondence: Jed A Lusthaus Glaucoma Unit, Sydney Eye Hospital, Sydney, New South Wales, Australia Email jed.lusthaus@sydney.edu.au
Journal of Experimental Pharmacology 2020:12 539-548 
muscle into the supraciliary and suprachoroidal spaces, otherwise known as uveoscleral outflow. ${ }^{3}$

Glaucoma can be classified in many ways, but the simplest classification is based on the anterior chamber angle configuration. This gives rise to open-angle glaucoma (OAG) or angle-closure glaucoma (ACG). The difference is based on anatomical changes seen in ACG, which obstruct aqueous from draining via the conventional and unconventional outflow pathways. The same ocular hypotensive agents utilized in open-angle glaucoma are useful temporizing measures in ACG, but definitive surgical or laser interventions are ultimately required. Our discussion is focused on $\mathrm{OAG}$, for which medical therapy is often the mainstay of treatment, augmented by laser and surgery in advanced cases. Openangle glaucoma can be divided into primary open-angle glaucoma (POAG) and the secondary open-angle glaucomas, including exfoliative, pigmentary, uveitic, and phacolytic glaucoma. Secondary glaucomas often require specific treatment for their underlying causes alongside the use of ocular hypotensive drop therapies and filtration surgery.

Lowering of IOP has been shown as the major modifiable risk factor for both glaucoma and OHT. A $20 \%$ reduction in IOP reduced the rate of progression from OHT to glaucoma and also delayed glaucoma onset when compared with untreated patients with $\mathrm{OHT}^{4}$ Glaucoma is a progressive disease with morbidity linked to the duration of disease. Treatment of OHT may reduce the risk or limit the amount of irreversible vision loss later in life.

\section{Current Treatment Options}

Two main mechanisms can be exploited when reducing IOP; suppressing aqueous production or increasing aqueous outflow. Topical and systemic therapy can be used to independently treat raised IOP, or augment surgical or laser techniques, in order to reduce the rate of glaucoma progression.

\section{Aqueous Suppressants}

Topical eye drops that decrease aqueous production include beta-blockers ( $\beta$ blockers), carbonic anhydrase inhibitors, and alpha-2 $(\alpha 2)$ agonists. The latter act by simultaneously reducing aqueous production and increasing aqueous outflow. ${ }^{5,6}$

Beta-blockers (eg Timolol) used as topical agents in the treatment of glaucoma and OHT, may have systemic absorption, and so use in patients with asthma, chronic airflow limitation, or cardiac disease is generally avoided. ${ }^{7}$ Carbonic anhydrase inhibitors (CAIs) are available in both topical (eg Brinzolamide, Dorzolamide) and oral formulations (eg Acetazolamide). ${ }^{8}$ Despite limited IOP-lowering effect, topical CAIs remain beneficial as supplementary treatment options. Acetazolamide has a potent IOP-lowering effect but is also accompanied by an increased risk of potentially life-threatening systemic complications. ${ }^{9,10}$ Oral acetazolamide is beneficial either for acute IOP reduction, or as bridging therapy until surgery, or uncommonly as a longterm treatment for refractory glaucoma.

The use of alpha- 2 agonists (eg Brimonidine) is often limited by localised adverse effects in adults, such as ocular erythema and irritation. In children, these agents have also been known to cause central nervous system depression, fatigue, and fainting episodes. ${ }^{11-13}$

\section{Aqueous Outflow Facilitators}

Agents that exclusively reduce IOP by increasing aqueous outflow include prostaglandin analogues, cholinergic agonists, and Rho Kinase Inhibitors.

Prostaglandin analogues (PGA) result in both shortand long-term increases in unconventional aqueous outflow. ${ }^{14,15}$ PGAs (eg Latanoprost) have very few systemic side effects and are considered first-line therapy in glaucoma and OHT. However, they have local side effects that effect cosmesis and uncommonly potentiate intraocular inflammation. ${ }^{16,17}$

Cholinergic agonists (eg Pilocarpine) increase conventional aqueous outflow, however are less commonly used than other classes due to their poorly tolerated side effect profile, including myopic shift, nyctalopia, and increased risk of retinal tears and detachment. ${ }^{18-22}$

\section{New Agents}

More recent developments have seen Rho kinase (ROCK) inhibitors such as Netarsudil (Rhopressa ${ }^{\circledR}$ ) and Ripasudil approved for the treatment of glaucoma. This class has dual-benefits of IOP-lowering and neuroprotection. The IOP-lowering effect of ROCK inhibitors is due to a decrease in outflow facility through the conventional pathway, which results from modification of the trabecular meshwork and Schlemm's canal cytoskeletons. ${ }^{23-25}$ ROCK inhibitors are mostly used as adjunctive treatment because their IOP-lowering effect is modest compared with PGAs currently in use. ${ }^{26}$ As such, combination therapies such as Rocklatan (Netarsudil/Latanoprost) 
are a welcome advancement in the management of raised IOP. Side effects of topical ROCK inhibitors are predominantly local, including conjunctival hyperemia, and blepharitis. $^{26}$

A nitric oxide donor in recent use is latanoprostene bunod [(LBN) Vyzulta $\left.{ }^{\mathrm{TM}}\right]$. LBN has proven successful in lowering IOP as both a first-line monotherapy and an adjuvant treatment. ${ }^{27,28}$ As monotherapy, a mean IOP reduction from baseline of $7.3 \mathrm{mmHg}$ was achieved at the second visit (mean at 141 days from initiation), with higher IOP reduction achieved in eyes with baseline IOP $>21 \mathrm{mmHg} .{ }^{27}$ In this cohort of 125 eyes, LBN was well tolerated with one participant reporting ocular hyperaemia. In another study, the use of adjuvant LBN in 52 patients led to the withdrawal of 4 patients due to adverse effects. ${ }^{27,28}$

\section{Barriers to Current Medical Therapy}

As with other chronic diseases, the main barrier to managing glaucoma with IOP-lowering agents is patient adherence. The reason for this is multifactorial with situational lifestyle factors (such as lack of support for medication administration, poor understanding of management goals and competing health/life events) being most prominent. ${ }^{27}$ Complicated medication regimens also have a negative impact on patient adherence. Treatment can often be rationalized by using combination drugs and reduced-frequency dosing options to lessen the impact on the quality of life.

\section{Method}

To identify ocular hypotensive drugs in development, we performed a search of ClinicalTrials.gov, cross-checking drugs with the Adis Insight database, and the individual pharmaceutical company websites, publications, and pipeline information.

\section{Pipeline Drugs}

Emerging drugs use a number of new and traditional mechanisms to reduce IOP. The drugs discussed in our review are in development and range from preclinical trials to Phase III studies (Table 1).

\section{Prostaglandin Analogues}

Prostaglandin analogues reduce IOP by increasing uveoscleral outflow, which is also the case for novel PGAs. ${ }^{28}$ Currently available PGAs are prostaglandin F2 $\alpha$ pro-drugs that quickly lower IOP by relaxing the ciliary muscle. ${ }^{14}$ PGAs may also cause prolonged uveoscleral outflow due to matrix metalloproteinase-driven remodelling within the ciliary body. ${ }^{15}$ The efficacy of PGAs, combined with a favourable safety profile, has led to their use as first-line drugs in the treatment of POAG and OHT. $^{29}$ Further development of PGAs attempts to prolong drug action and reduce the rates of side effects.

\section{Sepetaprost}

Sepetaprost (formerly DE-126 or ONO-9056) is a dual prostaglandin EP3 and prostaglandin F2 $\alpha$ agonist. The Phase 2b ANGEL study was a dose-finding study of Sepetaprost against a benchmark of $0.005 \%$ Latanoprost, over a 12-week period, conducted in both American and Japanese populations with either POAG or OHT. ${ }^{30}$ Oncedaily dosing of Sepetaprost $0.002 \%$ was the most efficacious dose, resulting in $-7.0 \mathrm{mmHg}$ reduction from baseline IOP at 6 weeks, compared to $-2.7 \mathrm{mmHg}$ for the placebo group, and $-6.8 \mathrm{mmHg}$ in the Latonoprost group. $^{30}$ Sepetaprost $0.002 \%$ showed a favourable sideeffect profile with $34.1 \%$ reporting side effects in comparison to $50 \%$ of the Latanoprost cohort. $^{30}$ The most commonly reported side effect of Sepetaprost was hyperemia, but the drug was well tolerated overall.

\section{Omidenepag Isopropyl}

Omidenepag (formerly DE-117) is a selective, high-affinity prostaglandin EP2 receptor agonist. It is a pro-drug, which is hydrolyzed to its active form in the aqueous and produces IOP-lowering effects in rabbits, dogs, and monkeys (Sharif, Kirihara, et al 2020). ${ }^{31}$ A Phase 3 non-inferiority study against latanoprost was undertaken in a Japanese population with POAG or OHT, which revealed comparable IOPlowering effects at 4 weeks, with a non-inferiority margin of $1.5 \mathrm{mmHg}{ }^{32}$ The most commonly associated side effect was transient conjunctival hyperemia, followed by corneal thickening, with cases of macular oedema and iritis also noted. $^{31,33-35}$ Omidenepag Isopropyl is a promising treatment of POAG and OHT, with significant IOP-lowering effects both alone and in conjunction with other treatments. Due to its selective activation of EP2, it avoids some of the common adverse effects of commercially available PGAs, including abnormal eyelash growth. ${ }^{31,32}$

\section{Nitric Oxide Donors}

Nitric oxide (NO) and its downstream mediator, cyclic guanosine monophosphate (cGMP), work directly upon trabecular meshwork cells to induce relaxation. ${ }^{36}$ This reduces resistance and increases the conventional outflow facility. It is suggested that $\mathrm{NO}$ also relaxes vessels within 
Table I Developing IOP-Lowering Drugs

\begin{tabular}{|c|c|c|c|c|}
\hline Drug & Company & $\begin{array}{l}\text { Stage of } \\
\text { Development }\end{array}$ & Mechanism of Action & $\begin{array}{l}\text { Mechanism of IOP } \\
\text { Reduction }\end{array}$ \\
\hline $\begin{array}{l}\text { Sepetaprost (DE-I26/ } \\
\text { ONO-9056) }\end{array}$ & Santen Pharmaceutical & Phase Ilb & $\begin{array}{l}\text { Prostaglandin EP3 and F2 } \alpha \\
\text { agonist }\end{array}$ & Increased uveoscleral outflow \\
\hline $\begin{array}{l}\text { Omidenepag Isopropyl } \\
\text { (DE-II7) }\end{array}$ & Santen Pharmaceutical & $\begin{array}{l}\text { Approved in Japan and } \\
\text { South Korea } \\
\text { Phase III in USA }\end{array}$ & Prostaglandin EP2 agonist & Increased uveoscleral outflow \\
\hline $\begin{array}{l}\text { NCX } 470 \\
\text { (Bimatoprost-NO) }\end{array}$ & $\mathrm{NicO} x$ & Phase III & $\begin{array}{l}\text { Nitric oxide donor (alongside } \\
\text { prostaglandin F2 } \alpha \text { agonist) }\end{array}$ & Increased conventional outflow \\
\hline $\begin{array}{l}\text { AKB-9778/ } \\
\text { Razuprotafib }\end{array}$ & Aerpio Pharmaceuticals & Phase II & $\begin{array}{l}\text { Tyrosine protein kinase } 2 \\
\text { receptor activator }\end{array}$ & Increased conventional outflow \\
\hline $\mathrm{H}-1337$ & $\begin{array}{l}\text { Allysta Pharmaceuticals/D. } \\
\text { Western Therapeutics } \\
\text { Institute }\end{array}$ & Phase lla & Protein kinase inhibitor & Increased conventional outflow \\
\hline $\begin{array}{l}\text { SNJ-I656 (Y39983 or } \\
\text { RKI-983) }\end{array}$ & Senju Pharmaceutical & Phase II & Rho kinase inhibitor & Increased conventional outflow \\
\hline PHP-20I (AMA0076) & Amakem/pH Pharma & $\begin{array}{l}\text { Phase Ilb (entering } \\
\text { Phase III) }\end{array}$ & Rho kinase inhibitor & Increased conventional outflow \\
\hline ITRI-E-2I 2 & $\begin{array}{l}\text { Industrial Technology } \\
\text { Research Institute, Hsinchu, } \\
\text { Republic of China }\end{array}$ & $\begin{array}{l}\text { Preclinical study } \\
\text { completed }\end{array}$ & Rho kinase inhibitor & Increased conventional outflow \\
\hline TAK-639 (SHP639) & Takeda & Phase I & $\begin{array}{l}\text { C type natriuretic peptide } \\
\text { analogue }\end{array}$ & Increased conventional outflow \\
\hline $\begin{array}{l}\text { Bamosiran } \\
\text { (SYL0400 I2) }\end{array}$ & Sylentis & Phase II & $\begin{array}{l}\text { Small interference RNA } \\
\text { molecule which inhibits } \beta 2 \\
\text { adrenergic receptors }\end{array}$ & $\begin{array}{l}\text { Decreased aqueous humour } \\
\text { production }\end{array}$ \\
\hline FMIOI & Femta Pharmaceuticals & $\begin{array}{l}\text { Preclinical study } \\
\text { completed }\end{array}$ & $\begin{array}{l}\text { A3 adenosine receptor } \\
\text { modulator }\end{array}$ & $\begin{array}{l}\text { Increased conventional outflow } \\
\text { and Decreased aqueous } \\
\text { humour production }\end{array}$ \\
\hline
\end{tabular}

the distal conventional outflow tract beyond Schlemm's canal. Therefore, NO reduces IOP via dual mechanisms. ${ }^{35}$ Nitric oxide donors are required to overcome the short half-life of NO in vivo, instead of releasing NO to the target tissue once metabolised.

\section{NCX 470}

NCX 470 is a newly developed combination drug, also known as Bimatoprost-NO. Similar to latanoprostene bunod, NCX 470 is a combination of a nitric oxide donor and a prostaglandin F2 $\alpha$ agonist. This combined therapy aims to enhance the activity of Bimatoprost, which usually is associated with significant ocular hyperemia. Indeed, in monkeys, rabbits, and canines, this combination showed a greater IOP-lowering effect when compared to the same dose of bimatoprost alone. ${ }^{38}$ Phase III trials are planned to commence in America and China in late 2020, which may show greater efficacy and increased tolerance with reduced ocular hyperemia.

\section{$\alpha$-Antagonists}

Traditionally, $\alpha 2$-agonists have been used to lower IOP in the management of glaucoma. Now the focus has shifted to $\alpha$-antagonists as a possible IOP-lowering treatment.

Phentolamine $\left(\mathrm{Nyxol}^{\circledR}\right)$ is a developing $\alpha$-adrenergic antagonist, which is being investigated for multiple ocular indications. The ORION-1 Phase $2 \mathrm{~b}$ study showed no statistically significant decrease in IOP on day 15 , when compared to baseline; however, IOP-lowering effects seemed to be greater with a lower baseline IOP. $^{39}$ 
Phentolamine has a favourable side effect profile, with predominantly transient mild-to-moderate conjunctival hyperemia reported. ${ }^{39}$ Given its limitations in reducing IOP, it is likely that future phentolamine studies will focus on its other potential benefit, the reduction of nocturnal visual disturbances.

\section{Tyrosine Protein Kinase Receptor Activators AKB-9778/Razuprotafib}

AKB-9778 is a tyrosine protein kinase receptor 2 activator, which lowers IOP by increasing conventional aqueous outflow. ${ }^{40}$ Phase $1 \mathrm{~b}$ studies showed a statistically significant reduction in IOP from baseline in those administered AKB-9778, both alone, and in combination with a commonly used prostaglandin analogue. ${ }^{40}$ However, AKB-9778 achieved greater IOP reduction in those with higher baseline IOP. ${ }^{40}$ The only ocular side effect noted in the Phase $1 \mathrm{~b}$ study was minimal to mild hyperemia, which resolved by 8 hours post-dose. Phase 2 trials are planned for the second half of 2020 .

\section{Kinase Inhibitors}

\section{$\mathrm{H}-\mathrm{I} 337$}

$\mathrm{H}-1337$ is a protein kinase inhibitor, centred on leucinerich repeat kinase (LRRK2). Its presumed IOP-lowering mechanism is increased trabecular outflow. ${ }^{41,42}$ This protein kinase inhibitor was shown to have a prolonged duration of effect in rabbit and monkey models, where in the latter, it lasted over 24 hours. ${ }^{41,42} \mathrm{H}-1337$ has the potential for success, with no side effects noted in the animal studies, and a promising Phase 2a clinical trial was completed in $2018 .^{41,42}$

\section{Rho Kinase Inhibitors}

Rho kinase (ROCK) inhibitors have great potential in glaucoma, as they not only lower IOP through an increase in conventional aqueous outflow, but they also display neuroprotective effects, thought to have potential benefit in other neurodegenerative conditions such as Alzheimer's disease. $^{43}$

\section{$\mathrm{SNJ}-1656$}

SNJ-1656 (RKI-983 or Y 39,983) is a ROCK inhibitor that increases conventional outflow by up to $65.5 \%$ and thereby reduces IOP in rabbit, mice, and primate models. ${ }^{44,45}$ The IOP lowering effect of Y 39,983 was comparable to timolol and superior to latanoprost in one mouse study. ${ }^{45}$ A 7 -day Phase 2 study found $0.1 \%$ dosing of SNJ-1656 to be efficacious in lowering IOP from a baseline of $22 \mathrm{mmHg}$. As with many topical eye drops, SNJ-1656 is associated with side effects including conjunctival hyperemia, which occurred in all patients in the Phase 1 study and $60 \%$ of patients in the Phase 2 study. ${ }^{44,46,47}$

\section{PHP-20I}

The ROCK inhibitor PHP-201 (previously AMA0076) relaxes the smooth muscle of the trabecular meshwork, which increases aqueous outflow and lowers IOP. $^{48}$ It is a drug that is rapidly broken down to its inactive metabolite upon contact with the ocular surface. This limits its topical side effects such as conjunctival hyperemia. ${ }^{48}$ In a Phase 1b human study, AMA0076 achieved a mean IOP reduction of $3.7 \mathrm{mmHg}$, which was statistically significant when compared to placebo. ${ }^{49}$ A Phase $2 \mathrm{~b}$ dose-finding and safety study was completed in normal tension glaucoma patients with results not yet released. $\mathrm{pH}$ Pharma is currently planning Phase 3 clinical trials across China, Japan, and Korea. ${ }^{50}$

\section{ITRI-E-2I 2}

ITRI-E-212, like other ROCK inhibitors, reduces IOP by increasing aqueous outflow through the trabecular meshwork. In a rabbit model, ITRI-E-212 has been effective in lowering IOP by nearly $25 \%$ in normotensive rabbits, with an even greater reduction of $28.6 \%$ in hypertensive rabbits. ${ }^{51}$ These IOP-lowering effects were found to last for at least 6 hours following the once-daily dosing regimen utilized in this study. Similar to other ROCK inhibitors, ITRI-E-212 induced conjunctival hyperemia; however, in this study, the side effect was found to be mild and transient in nature. ${ }^{51}$ This agent may have potential future use in the treatment of glaucoma, and we await further human trials.

\section{Type Natriuretic Peptide Analogue TAK-639}

TAK-639 (previously SHP639) is a C-type natriuretic peptide analogue that is presumed to increase trabecular meshwork outflow. ${ }^{52}$ Initial studies using topical administration to penetrate the corneas of rabbits, dogs, and monkeys have been promising. ${ }^{53}$ Furthermore, this study found minimal systemic plasma concentrations of TAK-639, mostly noted in the early period post-instillation. ${ }^{53}$ 
A subsequent Phase 1 study showed twice-daily dosing of $0.6 \%$ TAK-639 did reduce IOP in participants. This was associated with minimal systemic exposure, and the most common adverse effects being ocular irritation and transient fluorescein staining of the cornea. ${ }^{52}$ These side effects were tolerated by the participants and did not result in any study withdrawals. ${ }^{52}$

\section{Small Interference RNA (siRNA) Bamosiran}

Bamosiran (SYL040012) is a siRNA, which inhibits $\beta 2$ adrenergic receptors. It was efficacious in a rabbit model, with reduced aqueous humour production, and IOP-lowering effects similar to dorzolamide and latanoprost. ${ }^{54,55}$ A Phase 2a dose-finding placebo-controlled study found $0.75 \%$ Bamosiran to be the optimal concentration for IOP lowering effect at 14 days; however, further Phase 2 data suggest that Bamosiran $1.125 \%$ was the only dose that was comparable to timolol $0.5 \%{ }^{56}$ It displayed non-inferiority, specifically in eyes with baseline IOP $>25 \mathrm{mmHg}$.

\section{Adenosine Receptor Modulators FMIOI}

FM101 is an A3 adenosine receptor modulator, which is currently in development for multiple indications, including glaucoma. This drug works by modifying the actions of adenosine, which is a regulator of inflammation and fibrosis, thereby increasing the digestion of collagen components within the trabecular meshwork and decreasing outflow resistance. ${ }^{57,58}$ FM101 oral formulations were administered to rats over a 28 -day period, in a study to ascertain dose-related safety. ${ }^{58}$ This was a safety and toxicity study that showed adverse effects including irregular respirations, transient anorexia, and diarrhoea. ${ }^{58}$ Further preclinical research in normotensive rabbits and glucocorticoid-induced glaucoma mice models found the two highest doses of FM101 $(500 \mu \mathrm{m}$ and $700 \mu \mathrm{m})$, taken once or twice per day, were comparable to the IOP-lowering effect of Xalatan. ${ }^{59}$ The peak IOP-lowering effect of FM101 was achieved at approximately 2 hours post-administration, whilst twice-daily dosing showed progressive IOPlowering to day 27 of administration. ${ }^{59}$ We await the results of a Phase 1 clinical trial in healthy volunteers that will assess safety, tolerability, and the pharmacokinetic profile of FM101.

\section{Beyond Topical Agents}

Our review focuses upon developing topical ocular hypotensive agents; however, alternative drug delivery methods are also being explored. In further attempts to mitigate the side effects of topical therapy, progress has been made in the fields of ocular implants, injections, and punctual plugs.

Drug-eluting implants can be categorised based on extraocular or intraocular placement (Table 2). Extraocular devices include bimatoprost rings that are nestled into the conjunctival fornices, drug-eluting punctal plugs and intracanalicular implants. Contact lenses are extraocular inserts that are familiar to patients and are being considered as drug-eluting devices. These have been tested during a week of continuous wear, with further research required to ascertain the duration of effect and optimal dosing. ${ }^{60}$

Intraocular devices with drug-eluting properties have been placed within the trabecular meshwork, as well as the intracameral space. $^{61}$ Difficulties with successful selfadministration of eye drops are well documented. Implants shift this responsibility from the patient to the clinician. This can improve treatment adherence and also significantly reduce the frequency of drug administration. ${ }^{62}$ A Phase II study of the iDose (Glaukos, San Clemente, CA, USA), a Travoprost eluting stent that is injected directly into the angle via a preloaded injector system, has demonstrated favourable safety and efficacy profiles prompting a Phase III study. ${ }^{63}$ Further IOPlowering options include intraocular injections of sustained-release compounds, with various sites of delivery such as intravitreal or suprachoroidal (eg GB-401 encapsulated microparticle or Clearside's microinjector). Durysta $^{\mathrm{TM}}$ is a Food and Drug Authority (FDA) approved intracameral $10 \mu \mathrm{m}$ Bimatoprost sustained-release (SR) implant. The majority of these implants degrade by 12 months, and further trials are underway to ascertain the efficacy and safety of other doses. ${ }^{64}$ Re-treatment is currently not recommended. These local delivery systems limit systemic complications by using lower doses and require less frequent administration. Another benefit of these devices over implants is that they are biodegradable and leave no permanent intraocular foreign material. ${ }^{61}$ However, local implants can also have drawbacks, which in the case of Durysta, include increased risk of corneal endothelial cell loss, the need for caution in patients with narrow angles and increased risk of macular oedema and intraocular inflammation. ${ }^{65}$ 
Table 2 Alternate Delivery Routes

\begin{tabular}{|c|c|c|c|c|}
\hline Route & Options & Brand Name - Stage (P/C/A) & Active Ingredient & Duration \\
\hline \multirow[t]{3}{*}{ Extra-ocular } & \multirow[t]{2}{*}{ Surface implants } & Bimatoprost ring - C & Bimatoprost & 6 months \\
\hline & & $\begin{array}{l}\text { Topical Ophthalmic Drug Delivery } \\
\text { Device (TODDD) - C } \\
\text { Drug-eluting contact lenses - P }\end{array}$ & $\begin{array}{l}\text { Can hold a number of agents: Timolol, } \\
\text { Latanoprost, Brimonidine, Pilocarpine } \\
\text { Latanoprost }\end{array}$ & $\begin{array}{l}6 \text { months } \\
\text { I week }\end{array}$ \\
\hline & $\begin{array}{l}\text { Punctal plugs } \\
\text { Gel forming drops }\end{array}$ & $\begin{array}{l}\text { OTX-TP and Evolute - C } \\
\text { SoliDrop - P }\end{array}$ & $\begin{array}{l}\text { Travoprost or Latanoprost } \\
\text { Brimonidine }\end{array}$ & $\begin{array}{l}\text { 2-3 months } \\
\text { Weeks }\end{array}$ \\
\hline \multirow[t]{4}{*}{ Intra-ocular } & \multicolumn{4}{|l|}{ Injectables } \\
\hline & $\begin{array}{l}\text { - Supraciliary } \\
\text { - Subconjunctival and } \\
\text { Intravitreal } \\
\text { - Anterior Chamber }\end{array}$ & $\begin{array}{l}\text { Clearside - P } \\
\text { GB-40I - P } \\
\text { IBI-60,089 - P }\end{array}$ & $\begin{array}{l}\text { Brimonidine } \\
\text { Proprietry } \beta \text {-adrenergic antagonist prodrug } \\
\text { Sustained release Latanoprost }\end{array}$ & $\begin{array}{l}1 \text { month } \\
6 \text { months } \\
6 \text { months }\end{array}$ \\
\hline & \multicolumn{4}{|l|}{ Implants } \\
\hline & $\begin{array}{l}\text { - Intracameral } \\
\text { - Trabecular meshwork } \\
\text { - Intrascleral } \\
\text { - Subconjunctival }\end{array}$ & $\begin{array}{l}\text { Durysta }^{\mathrm{TM}} \text { - A } \\
\text { ENV5I5 - C } \\
\text { LATA-CSI02 - C } \\
\text { iDose - C } \\
\text { Ophthalmic MicroPump - P } \\
\text { Durasert - C }\end{array}$ & $\begin{array}{l}\text { Bimatoprost SR } \\
\text { Travoprost XR } \\
\text { Latanoprost FA SR } \\
\text { Travoprost } \\
\text { Various drugs } \\
\text { Various agents. Latanoprost being trialled }\end{array}$ & $\begin{array}{l}6 \text { months } \\
\text { II months } \\
\text { Up to } 32 \text { weeks } \\
12 \text { months } \\
12 \text { months } \\
12 \text { months }\end{array}$ \\
\hline
\end{tabular}

Notes: P, preclinical trials; C, clinical trials; A, FDA approved.

\section{Conclusion}

Glaucoma is a condition with significant associated morbidity, and the goal is to find IOP-lowering therapy that is effective, simpler to use and can complement/augment the options already available to the patient. There are promising new agents in classes that are already in use, and also agents in novel classes that may provide IOP control and in some cases, neuroprotection. Newer agents that are in development may be useful as adjunctive medical therapy and may also delay or avoid non-medical treatment.

While there are patients who will progress to require interventional IOP-lowering procedures, most will achieve adequate IOP control with adherence to topical medication. Poor adherence to treatment is often the cause behind treatment failure and is due to increased frequency of dosing or number of medications, as well as an unfavourable side effect profile. Therefore, future IOP-lowering therapies need to address these issues to improve patient outcomes.

Currently available PGAs, and those in development, have significant IOP-lowering effect. Both Sepetaprost and Omidenepag Isopropyl are promising PGAs that have been shown to have comparable IOP-lowering effect to latanoprost, but with more favourable side effect profiles. These agents are likely to be first-line therapies, with the added benefit of potentially improved patient tolerance and adherence, compared with current PGAs.

Enhancing or augmenting the effects of currently effective agents is a promising direction for medical therapy in glaucoma. NCX 470 is a combination drug that is present in late-phase trials. By adding a nitric oxide donor to bimatoprost, it is hoped that clinicians will be able to theoretically improve IOP-lowering without increasing medication instillation frequency. This combination has the potential for improving the effect of an existing efficacious PGA, as well as reducing patient intolerance, owing to the drug's favourable side effect profile.

Rho-Kinase Inhibitors, such as Netarsudil and Ripasudil, are recent additions in the management of glaucoma. This drug class also appears to have an additional neuroprotective effect making it an attractive option as a first-line agent. Ripasudil in particular has a favourable side effect profile compared to some currently available therapies. Its main side effect is moderate severity conjunctival hyperemia, which tends to resolve within 120 minutes. ${ }^{66}$ Future ROCK inhibitors, SNJ-1656, PHP-201, and ITRI-E-212, have a similar limited side effect profile with impressive IOP-lowering efficacy. We anticipate 
these drugs will be well tolerated and will be a positive development in expanding treatment options.

Some of the novel drug classes also appear to have great potential in improving patient adherence, as well as being effective in lowering IOP. For example, the protein kinase inhibitor H-1337 had a long duration of effect (lasting over 24 hours in monkeys) with no side effects noted in the Phase 1 and 2a trials. Further studies are required to test whether the drug will consistently perform in larger human trials. The favourable side effect profile and daily (or possibly less frequent) dosing of $\mathrm{H}-1337$ are encouraging features for its potential use in clinical practice. Bamosiran is a siRNA that also shows potential in lowering IOP, but its success seems to be limited to patients with a higher pre-treatment IOP.

Topical ocular hypotensive agents currently in development aim to improve patient adherence to treatment. For the majority of new agents, this is achieved through improved side effect profiles, which results in better tolerance. Some agents (such as H-1337) also act to increase efficacy and reduce the frequency of dosing. Rationalisation of patient medication regimens is possible with current fixed-combination therapies. Further combination eye drop formulations are in development, and will similarly take advantage of this method to improve the IOP-lowering effect and patient adherence.

Alternative treatment delivery options including drugeluting punctal plugs, conjunctival/forniceal rings and intracameral inserts, are an attractive way to improve treatment adherence and tolerability. However, these options come with a different set of potential adverse events owing to their invasive nature. Oral administration is another mode of drug delivery, but is associated with the potential for systemic adverse events and has traditionally been underutilized.

Non-medical therapies that have recently changed the landscape of glaucoma practice include surgical devices and selective laser trabeculoplasty. Multiple minimally invasive glaucoma surgical (MIGS) devices have been introduced to either independently lower IOP or work alongside medical therapy. They carry their own set of adverse events, including rare, but potentially sightthreatening intraoperative and post-operative complications. Selective laser trabeculoplasty has also found a role in newly diagnosed ocular hypertensives and openangle glaucoma patients. ${ }^{67}$ The favourable adverse effect profile is a major advantage of SLT, but conversely, the period of efficacy is variable and limited. These practice- changing alternatives have provided the clinician with more choice; however, the role of medical therapy remains important as first-line or adjunctive therapy. Although most of the medications mentioned in this review offer similar or slightly less IOP-lowering effect than currently available therapies, their favourable side effect profiles appear to be promising.

Ultimately, glaucoma research aims to improve outcomes through disease modification. The main targets in medication research are the IOP-lowering effect and concurrently, the drug's safety profile. Numerous pipeline drugs may offer these benefits and possibly prevent patients from undergoing invasive interventions.

\section{Disclosure}

The authors report no conflicts of interest for this work.

\section{References}

1. Kass MA, Heuer DK, Higginbotham EJ, et al. The ocular hypertension treatment study: a randomized trial determines that topical ocular hypotensive medication delays or prevents the onset of primary open-angle glaucoma. Arch Ophthal. 2002;120(6):701-713. doi:10.1001/archopht.120.6.701

2. Medeiros FA, Weinreb RN, Sample PA, et al. Validation of a predictive model to estimate the risk of conversion from ocular hypertension to glaucoma. Arch Ophthal. 2005;123(10):1351-1360. doi:10.1001/archopht.123.10.1351

3. Johnson M, McLaren JW, Overby DR. Unconventional aqueous humor outflow: a review. Exp Eye Res. 2017;158:94-111. doi:10. 1016/j.exer.2016.01.017

4. Gordon MO, Beiser JA, Brandt JD, et al. The ocular hypertension treatment study: baseline factors that predict the onset of primary open-angle glaucoma. Arch Ophthal. 2002;120(6):714-720. doi:10. 1001/archopht.120.6.714

5. Cantor LB. Brimonidine in the treatment of glaucoma and ocular hypertension. Ther Clin Risk Manag. 2006;2(4):337.

6. Reitsamer HA, Posey M, Kiel JW. Effects of a topical $\alpha 2$ adrenergic agonist on ciliary blood flow and aqueous production in rabbits. Exp Eye Res. 2006;82(3):405-415. doi:10.1016/j.exer.2005.07.015

7. Zimmerman TJ. Topical ophthalmic beta blockers: a comparative review. J Ocul Pharmacol Ther. 1993;9(4):373-384. doi:10.1089/ jop.1993.9.373

8. Maren TH. Carbonic anhydrase: general perspective and advances in glaucoma research. Drug Dev Res. 1987;10(4):255-276. doi:10.1002/ ddr.430100407

9. Farzam K, Abdullah M. Acetazolamide. StatPearls [Internet]. StatPearls Publishing; 2019.

10. Katayama F, Miura H, Takanashi S. Long-term effectiveness and side effects of acetazolamide as an adjunct to other anticonvulsants in the treatment of refractory epilepsies. Brain Dev. 2002;24(3):150-154. doi:10.1016/S0387-7604(02)00003-7

11. Cantor LB. The evolving pharmacotherapeutic profile of brimonidine, an 2-adrenergic agonist, after four years of continuous use. Expert Opin Pharmacother. 2000;1(4):815-834. doi:10.1517/14656 566.1.4.815

12. Bowman RJC, Cope J, Nischal KK. Ocular and systemic side effects of brimonidine $0.2 \%$ eye drops (Alphagan ${ }^{\circledR}$ ) in children. Eye. 2004;18(1):24-26. doi:10.1038/sj.eye.6700520 
13. Scahill L. Alpha-2 adrenergic agonists in children with inattention, hyperactivity and impulsiveness. CNS Drugs. 2009;23(Supplement 1):43-49. doi:10.2165/00023210-200923000-00006

14. Stamer WD, Piwnica D, Jolas T, et al. Cellular basis for bimatoprost effects on human conventional outflow. Invest Ophthal. 2010;51 (10):5176-5181. doi:10.1167/iovs.09-4955

15. Oh DJ, Martin JL, Williams AJ, et al. Analysis of expression of matrix metalloproteinases and tissue inhibitors of metalloproteinases in human ciliary body after latanoprost. Invest Ophthal. 2006;47 (3):953-963. doi:10.1167/iovs.05-0516

16. Holló G. The side effects of the prostaglandin analogues. Expert Opin Drug Saf. 2007;6(1):45-52. doi:10.1517/14740338.6.1.45

17. Alm A, Grierson I, Shields MB. Side effects associated with prostaglandin analog therapy. Surv Ophthalmol. 2008;53(Suppl1):S93105. doi:10.1016/j.survophthal.2008.08.004

18. Khaw PT, Shah P, Elkington AR. Glaucoma-2:Treatment. BMJ. 2004;328(7432):156-158. doi:10.1136/bmj.328.7432.156

19. Skaat A, Rosman MS, Chien JL. Effect of pilocarpine hydrochloride on the Schlemm canal in healthy eyes and eyes with open-angle glaucoma. JAMA Ophthal. 2016;134(9):976-981. doi:10.1001/ jamaophthalmol.2016.1881

20. Puustjärvi T. Retinal detachment during glaucoma therapy. Ophthalmologica. 1985;190(1):40-44. doi:10.1159/000309490

21. Singh M. Miotic-induced retinal detachment: a case report. Med $J$ Malaysia. 1985;40(2).

22. Kinney M, Johnson A, Reddix M, McCann MB. Temporal effects of $2 \%$ pilocarpine ophthalmic solution on human pupil size and accommodation. Mil Med. 2020;185(Supplement_1):435-442. doi:10.1093/milmed/usz235

23. Honjo M, Inatani M, Kido N, et al. Effects of protein kinase inhibitor, HA1077, on intraocular pressure and outflow facility in rabbit eyes. Arch Ophthal. 2001;119(8):1171-1178. doi:10.1001/archopht.119.8. 1171

24. Honjo M, Hidenobu T, Inatani M, et al. Effects of rho-associated protein kinase inhibitor Y-27632 on intraocular pressure and outflow facility. Invest Ophthal. 2001;42(1):137-144.

25. Rao PV, Deng P, Kumar J, Epstein DL. Modulation of aqueous humor outflow facility by the Rho kinase-specific inhibitor Y-27632. Invest Ophthal. 2001;42(5):1029-1037.

26. Tanna AP, Johnson M. Rho kinase inhibitors as a novel treatment for glaucoma and ocular hypertension. Ophthalmology. 2018;125 (11):1741-1756. doi:10.1016/j.ophtha.2018.04.040

27. Okeke C, Cooper MS, Brinkley D, Deom J, Thimons J. Latanoprostene bunod ophthalmic solution $0.024 \%$ in patients with glaucoma or ocular hypertension new to pharmacotherapy. Invest Ophthal. 2020;61(7):4260.

28. Sharma H, Radell KE, Gagliuoso D, Chadha N, Tsai JC, Serle J. First year real world clinical experience with latanoprostene bunod. Invest Ophthal. 2020;61(7):1244.

29. Tsai JC, McClure CA, Ramos SE, Schlundt DG, Pichert JW. Compliance barriers in glaucoma: a systematic classification. J Glaucoma. 2003;12(5):393-398. doi:10.1097/00061198-2003100 00-00001

30. Doucette LP, Walter MA. Prostaglandins in the eye: function, expression, and roles in glaucoma. Ophthalmic Genet. 2017;38(2):108-116. doi:10.3109/13816810.2016.1164193

31. van der Valk R, Webers CAB, Schouten JSAG, Zeegers MP, Hendrikse F, Prinz MH. Intraocular pressure-lowering effects of all commonly used glaucoma drugs: a meta-analysis of randomized clinical trials. Ophthalmology. 2005;112(7):1177-1185. doi:10.1016/ j.ophtha.2005.01.042

32. Inman S, Wirta DL Sepetaprost is safe, effective for IOP reduction in POAH and OHT. HCP Live Conference Coverage; 2019. Available from: https://www.mdmag.com/conference-coverage/aao2019/sepetaprost-safe-effective-for-iop-reduction-in-poah-and-oht. Accessed May 12, 2020.
33. Sharif NA, Kirihara T, Iwamura R, et al. A novel non-prostaglandin EP2-receptor agonist for glaucoma treatment: omidenepag isopropyl (DE-117). FASEB J. 2020;34(S1):1. doi:10.1096/fasebj.2020.34.s1.08817

34. Lu F, Aihara M, Kawata H, Iwata A, Odani-Kawabata N, Shams NK. A phase 3 trial comparing omidenepag isopropyl $0.002 \%$ with latanoprost $0.005 \%$ in primary open-angle glaucoma and ocular hypertension: the AYAME study. Invest Ophthal. 2018;59(9):1235.

35. Aihara M, Lu F, Kawata H, et al. Phase 2, randomized, dose-finding studies of omidenepag isopropyl, a selective EP2 agonist, in patients with primary open-angle glaucoma or ocular hypertension. J Glaucoma. 2019;28(5):375-385. doi:10.1097/IJG.0000000000001221

36. Dismuke WM, Liang J, Overby DR, Stamer WD. Concentrationrelated effects of nitric oxide and endothelin-1 on human trabecular meshwork cell contractility. Exp Eye Res. 2014;120:28-35. doi:10. 1016/j.exer.2013.12.012

37. de Kater AW, Spurr-Michaud SJ, Gipson IK. Localization of smooth muscle myosin-containing cells in the aqueous outflow pathway. Invest Ophthal. 1990;31(2):347-353.

38. Impagnatiello $\mathrm{F}$, Toris $\mathrm{CB}$, Batugo $\mathrm{M}$, et al. Intraocular pressurelowering activity of NCX 470, a novel nitric oxide-donating bimatoprost in preclinical models. Invest Ophthal. 2015;56(11):65 58-6564. doi:10.1167/iovs.15-17190

39. businesswire [page on the internet] businesswire. A Berkshire Hathaway company: ocuphire pharma announces results from two phase 2 clinical studies of nyxol eye drops; 2019. Available from: https:/www.businesswire.com/news/home/20191107005535/en/ Ocuphire-Pharma-Announces-Results-Phase-2-Clinical\#: :text= Drops $\% 20 \% 7 C \% 20$ Business $\% 20$ Wire-,Ocuphire $\% 20 \mathrm{Pharma} \%$ 20Announces $\% 20$ Results $\% 20$ from $\% 20$ Two $\% 20$ Phase $\% 202$,of\% $20 \mathrm{Nyxo1} \% \mathrm{C} 2 \%$ AE $\% 20$ Eye $\% 20$ Drops\&text=FARMINGTON $\%$ 20HILLS $\% 2$ C $\% 20$ Mich.\&text=Results $\% 20$ included $\% 20 \mathrm{a} \% 20$ clear $\%$ 20improvement,both\%20acute $\% 20$ and $\% 20$ chronic\%20settings. Accessed May 13, 2020.

40. Peters K; for Aerpio Pharmaceuticals Inc. AKB-9778: a Novel Approach to Glaucoma Treatment Targeting Tie2 in the Conventional Outflow Pathway. Proceedings of the Glaucoma 360 New Horizons in Pharmaceuticals Conference. 2020

41. Hidaka H, Sumi K, Izuhara T, Kasai A, Tanimoto H. A novel isoquinoline sulfonamide protein kinase inhibitor $(\mathrm{H}-1337)$ produces long-lasting reduction of IOP. Invest Ophthal. 2015;56(7):5712.

42. dwti.co.jp [webpage on the Internet]. H-1337 (Product Pipeline of D. Western Therapeutics Institute); 2000. Available from: https:// www.dwti.co.jp/english/business-outline/product-pipeline/h-1337. Accessed June 21, 2020.

43. Abbhi V, Piplani P. Rho-kinase (ROCK) inhibitors a neuroprotective therapeutic paradigm with a focus on ocular utility. Curr Med Chem. 2020;27(14):2222-2256.

44. Tokushige H, Inatani M, Nemoto S, et al. Effects of topical administration of y-39983, a selective rho-associated protein kinase inhibitor, on ocular tissues in rabbits and monkeys. Invest Ophthal. 2007;48 (7):3216-3222. doi:10.1167/iovs.05-1617

45. Whitlock NA, Harrison B, Mixon T, et al. Decreased intraocular pressure in mice following either pharmacological or genetic inhibition of ROCK. J Ocul Pharmacol Ther. 2009;25(3):187-194. doi:10.1089/jop.2008.0142

46. Tanihara H, Masaru I, Honho M, Tokushige H, Azuma J, Araie M. Intraocular pressure-lowering effects and safety of topical administration of a selective ROCK inhibitor, SNJ-1656, in healthy volunteers. Arch Ophthal. 2008;126(3):309-315. doi:10.1001/archophthalmol.2007.76

47. Inoue T, Tanihara H, Tokushige H, Araie M. Efficacy and safety of SNJ-1656 in primary open-angle glaucoma or ocular hypertension. Acta Ophthalmol. 2015;93(5):e393-e395. doi:10.1111/aos.12641

48. aao.org [webpage on the Internet]; Karmel M. Glaucoma pipeline drugs: targeting the trabecular meshwork. EyeNet Magazine; 2013. Available from https://www.aao.org/eyenet/article/glaucoma-pipeline -drugs-targeting-trabecular-meshw. Accessed June 13, 2020. 
49. PRNewswire [Webpage]. Amakem therapeutics presents positive top-line clinical results for AMA0076 for glaucoma at ophthalmology innovation summit. Proceedings of the ophthalmology innovation summit; 2013. Diepenbeek, Belgium. PR Newswire. Available from https://www.prnewswire.com/news-releases/amakem-presentspositive-top-line-clinical-results-for-ama0076-for-glaucoma-atophthalmology-innovation-summit-231913301.html. Accessed June $21,2020$.

50. pH-pharma.com [webpage on the Internet]. $\mathrm{pH}$ pharma proprietary pipeline: PHP-201; 2018. Available from http://www.ph-pharma. com/en/portfolio/page01.html\#PHP201. Accessed June 21, 2020.

51. Hsu C, Chen Y, Liu C, et al. A highly selective Rho-kinase inhibitor (ITRI-E-212) potentially treats glaucoma upon topical administration with low incidence of ocular hyperemia. Invest Ophthal. 2019;60 (2):624-633. doi:10.1167/iovs.18-25252

52. Martin P, Cohen A, Uddin S, Epelbaum L, Josiah S. Randomized, double-masked, placebo-controlled dose escalation study of TAK-639 topical ophthalmic solution in subjects with ocular hypertension or primary open-angle glaucoma. Clin Ophthal. 2020;14:885. doi:10. 2147/OPTH.S242932

53. Savinainen A, Prusakiewicz JJ, Oswald J, et al. Pharmacokinetics and intraocular pressure-lowering activity of TAK-639, a novel C-type natriuretic peptide analog, in rabbit, dog, and monkey. Exp Eye Res. 2019;189:107836. doi:10.1016/j.exer.2019.107836

54. Gupta SK, Agarwal R, Galpalli ND, Srivastava S, Agrawal SS, Saxena R. Comparative efficacy of pilocarpine, timolol and latanoprost in experimental models of glaucoma. Methods Find Exp Clin Pharmacol. 2007;29(10):665-672. doi:10.1358/mf.2007.29.10.1147 765

55. Martínez T, González MV, Roehl I, Wright N, Pañeda C, Jiménez AI. In vitro and in vivo efficacy of SYL040012, a novel siRNA compound for treatment of glaucoma. Mol Ther. 2014;22(1):81-91.

56. Sylentis.com [webpage on the Internet]. R\&D products: bamosiran. Sylentis; 2020. Available from https://www.sylentis.com/index.php/ en/pipeline/bamosiran. Accessed June 21, 2020.

57. Lu LJ, Tsai JC, Liu J. Focus: drug development: novel pharmacologic candidates for treatment of primary open-angle glaucoma. Yale J Biol Med. 2017;90(1):111.

58. Park C, Han C, Sakaguchi Y, Lee J, Youn H. Safety evaluation of FM101, an A3 adenosine receptor modulator, in rat, for developing as therapeutics of glaucoma and hepatitis. EXCLI J. 2020;19:187.
59. worldglaucoma.net [webpage on the Internet]; Lee S, Yang J, Park C, Lee H, Lee M. Efficacy, pharmacokinetic and non-clinical safety profile of a novel A3AR antagonist, FM101, in the treatment of glaucoma by oral administration; 2017. Available from: https:/wga. one/WGC/2017/wgc2017_thefiles/uploads/ninja-forms/6/2017\% 20WGC\%20-\%20Poster-Final.pdf. Accessed September 29, 2020.

60. Ciolino JB, Ross AE, Tulsan R, et al. Latanoprost-eluting contact lenses in glaucomatous monkeys. Ophthalmology. 2016;123 (10):2085-2092. doi:10.1016/j.ophtha.2016.06.038

61. Shalaby WS, Shankar V, Razeghinejad R, Katz LJ. Current and new pharmacotherapeutic approaches for glaucoma. Expert Opin Pharmacother. 2020;1-14. doi:10.1080/14656566.2020.1795130

62. Hennessy AL, Katz J, Covert D, Protzko C, Robin AL. Videotaped evaluation of eyedrop instillation in glaucoma patients with visual impairment or moderate to severe visual field loss. Ophthalmology. 2010;117(12):2345-2352. doi:10.1016/j.ophtha.2010.03.040

63. Glaukos. Glaukos corporation's idose ${ }^{\mathrm{TM}}$ travaprost achieves sustained IOP reduction and favorable safety profile in 12-month interim cohort; 2018. Available from: http://investors.glaukos.com/investors/ press-releases/press-release-details/2018/Glaukos-Corporations-

iDose-Travoprost-Achieves-Sustained-IOP-Reduction-and-Favorable -Safety-Profile-in-12-Month-Interim-Cohort/default.aspx. Accessed November 3, 2020.

64. Craven ER, Walters T, Christie WC, et al. 24-month phase I/II clinical trial of bimatoprost sustained-release implant (Bimatoprost SR) in glaucoma patients. Drugs. 2020;80(2):167-179. doi:10.1007/ s40265-019-01248-0

65. Allergen. DurystaTM (bimatoprost implant), for intracameral administration: US prescribing information; 2020. https://media.allergan. com/products/durysta_pi.pdf. Accessed April 20, 2020.

66. Tanihara $\mathrm{H}$, Inoue $\mathrm{T}$, Yamamoto $\mathrm{T}$, et al. Phase 2 randomized clinical study of a Rho kinase inhibitor, K-115, in primary open-angle glaucoma and ocular hypertension. Am J Ophthal. 2013;156(4):731-736. e732. doi:10.1016/j.ajo.2013.05.016

67. Gazzard G, Konstantakopoulou E, Garway-Heath D, et al. Selective laser trabeculoplasty versus eye drops for first-line treatment of ocular hypertension and glaucoma (LiGHT): a multicentre randomised controlled trial. Lancet. 2019;393(10180):1505-1516.

\section{Publish your work in this journal}

The Journal of Experimental Pharmacology is an international, peerreviewed, open access journal publishing original research, reports, reviews and commentaries on all areas of laboratory and experimental pharmacology. The manuscript management system is completely online and includes a very quick and fair peer-review system. Visit http://www.dovepress.com/testimonials.php to read real quotes from published authors. 